Brazilian Journal

of Chemical

ISSN 0104-6632

Engineering

Printed in Brazi

www.scielo.br/bjce

Vol. 34, No. 03, pp. 811 - 819, July - September, 2017

(cc) EY

dx.doi.org/10.1590/0104-6632.20170343s20150691

\title{
ETHANOLIC BIODIESEL PRODUCTION: A COMPARATIVE STUDY BETWEEN A PLUG FLOW REACTOR AND REACTIVE DISTILLATION
}

\author{
R. J. M. C. L. Silva, T. P. C. Souza, J. P. Silva, \\ J. G. A. Pacheco and J. M. F. Silva* \\ Universidade Federal de Pernambuco, Department of Chemical Engineering, \\ Laboratory of Refining Process and Clean Technologies, Av Arthur de Sá, s/n, 50740-521 Recife, PE, Brazil \\ *E-mail: jmfs@ufpe.br; Phone: +55 8121267272 \\ E-mail: ronaldymiller@hotmail.com, thiberio_souza@hotmail.com,josivan_silva@hotmail.com, \\ geraldo.ufpe@gmail.com,jmfs@ufpe.br
}

(Submitted: October 31, 2015; Revised: March 10, 2016; Accepted: April 9, 2016)

\begin{abstract}
The interest in biodiesel as an alternative source of energy has been extremely intensified by its use as a renewable and economically viable fuel. As a result, continuous production processes have been a requirement to supply growing demand. This work presents experimental and simulated results of two biodiesel production pilot plants and makes a comparison between the processes they use. The first one was designed with three plug flow reactors (PFRs) connected with recycle streams. The second one was composed of a reactive distillation process for biodiesel production. Repeated tests in Aspen Plus and Matlab showed that multiple PFRs with high volume are required for $98 \%$ ester conversion. However, a single unit of reactive distillation resulted in $99 \%$ conversion. In short, to produce large quantities of biodiesel this work indicates continuous reactive distillation as the most adequate process.
\end{abstract}

Keywords: biodiesel, plug-flow reactors, reactive distillation, Aspen Plus.

\section{INTRODUCTION}

The American Society for Testing and Materials defines biodiesel as a fuel composed of mono-alkyl esters of long chain fatty acids derived from vegetable oil or animal fat, respecting the requirements of ASTM D6751-12 (ASTM, 2012). Considering the available biofuel sources, biodiesel has significant importance in modern society. This is because it is biodegradable, nontoxic, an excellent lubricant and can be used pure or blended with petroleum diesel (Jain et al., 2012). Biodiesel can be obtained from an acid-catalyzed esterification or by a base-catalyzed transesterification reaction, which generates glycerin as byproduct thus increasing the economic value of the process (Yang et al., 2012). American Legislation permits
$20 \%$ of biodiesel to be added to commercial diesel, in compliance with regulation ASTM D6751 (ASTM, 2012).

Significant efforts have been made to adapt raw material and the productive process to the quality of biodiesel production. For instance, Teo et al. (2014) have recently described the production of biodiesel from micro algae using a base-catalyzed transesterification reaction. Choedkiatsakul et al. (2014) showed an improved transesterification reaction by combining mechanical stirring and ultrasonic reactor. Alves et al. (2013) studied biodiesel purification using micro and ultrafiltration membranes.

The main raw materials for biodiesel production include palm, canola, jatropha, soybeans, cotton seed and sunflower seed. These oilseeds are attractive due to their

\footnotetext{
* To whom correspondence should be addressed
} 
availability and possibility of ester production on a large scale. There is a certain critcism, however, regarding the use of soybean as raw material for biofuel production. Being a food commodity, use for fuel does not support a global policy of food security (Pinto et al., 2005; Joseph, 2007; Festel, 2008). Cottonseed oil appears to be an effective substitute for soybean oil as it is a byproduct of the cotton industry (Qian, 2008).

According to the report of the Energy Information Administration (EIA), in the United States the total domestic consumption of renewable energy will reach 36 percent in 2035. Renewable energy is the world's fastestgrowing source of market energy, the demand for which is estimated to rise by an average of 3.0 percent per year between 2010 and 2035 (EIA, 2014).

Given this situation, it is fundamental to find conversion processes that are both economically and environmentally viable. According to Fogler (1999), Plug Flow Reactors operate at high production rates. Our laboratory has built a continuous mini pilot plant for biodiesel production with three of these reactors, including an individual recycling system. Another extremely important continuous process is the reactive distillation technique. Since its development in the past decade, it has become the key force for meeting high production demands in some process (Beckmann et al., 2002). It consists of an innovative process unit where the chemical reaction and separation of products happen simultaneously inside the same equipment. The distillation column has a reactive section combined with nonreactive rectifying and stripping sections (Souza et al., 2014). A major characteristic of this technique is that conversions close $100 \%$ can be reached (Holtbruegge et al., 2014; Anton Kiss, 2011; He et al., 2006).

The traditional biodiesel production process via batch reactors requires a large excess of alcohol to shift the chemical equilibrium. It also has a long operating time. On the other hand, the reactive distillation technique makes it possible to minimize the alcohol volumetric flow, since it is continuously being recycled at the top of the column (Souza et al., 2014; Boon-anuwat et al., 2015). Indeed, this technique can process a high amount of raw material in a short time interval as a continuous process (Boon-anuwat et al., 2015). When it comes to economic viability, several authors have demonstrated that this technique is potentially low cost. For example, Simasatitkul et al. (2011) emphasizes that in this process the transesterification reaction is carried out more completely and there is also a decreased processing cost of reactants in excess. Gomez-Castro et al. (2010) simulated the use of a thermally coupled reactive distillation and suggested that this modified system can be designed to reduce the energy consumption for methanolic biodiesel production at high pressures. Machado et al. (2013) explained that one of the major advantages of this technique is the aspect of saving energy during the reboiler operation, which is crucial for obtaining high quality products (Ignat and Kiss, 2013).

In line with this innovative continuous technique, the Fuel Laboratory at the Federal University of Pernambuco has a pilot plant for biodiesel production by reactive distillation, which is controlled by hardware communication. The command software system was created in a Delphi environment with Pascal Language. The analysis of ester was performed by gas chromatography following the EN 14103 method (EN 14103, 2011).

Our research aimed to obtain experimental data regarding biodiesel production processes via PFRs and reactive distillation and to compare them with those simulated in Aspen Plus. After developing the performance equation of these reactors with a recycle stream, it was possible to construct a 3D map in Matlab, showing the relationship between conversions, recycle ratios, and residence times. It was also possible to predict the most adequate configuration for a continuous production process of biodiesel on a large scale.

\section{MATERIAL AND METHODS}

\section{Biodiesel Production Process and Experimental Analysis}

Aspen Plus is a software commonly used in the chemical and petrochemical industries to evaluate process performance (Dharand Kirtanai, 2009). Triolein, ethanol and caustic soda were used to represent oil, alcohol and catalyst, respectively. $\mathrm{NaOH}$ was included in the alcohol stream, which was mixed with the oil stream before feeding the first reactor. Between the first and the second reactor there was a recycle stream that could assume different values. The product stream corresponded to ester, $\mathrm{NaOH}$, glycerin and unreacted oil and alcohol. The mini pilot plant for biodiesel production that uses PFRs with recycle streams is shown in Figure 1. The operating conditions of the pilot plant for biodiesel production via PFRs are shown in Table 1.

A glass reactive distillation column was built with one oil feeding point, one alcohol feeding point and six sampling points along the distillation column, a reflux system at the top and a total condenser (Fig. 2). A catalyst dosing system with three concentration levels, reboiler, pumping system for reactants and cooling water, volumetric flow meter system and regulator valve to establish the molar ratio between alcohol and oil were also integrated with the column system. The reactive distillation column was 1.5 $\mathrm{m}$ tall and $3 \mathrm{~cm}$ in diameter. It was packed with Raschig rings, $7 \mathrm{~mm}$ in diameter. The reactive distillation column was controlled by computer in order to obtain a high level of automaticity. Furthermore, a hardware supervisory system for communication between column and computer was developed. This supervisory system controlled the volumetric flow rates of oil and alcohol feeding the column, 


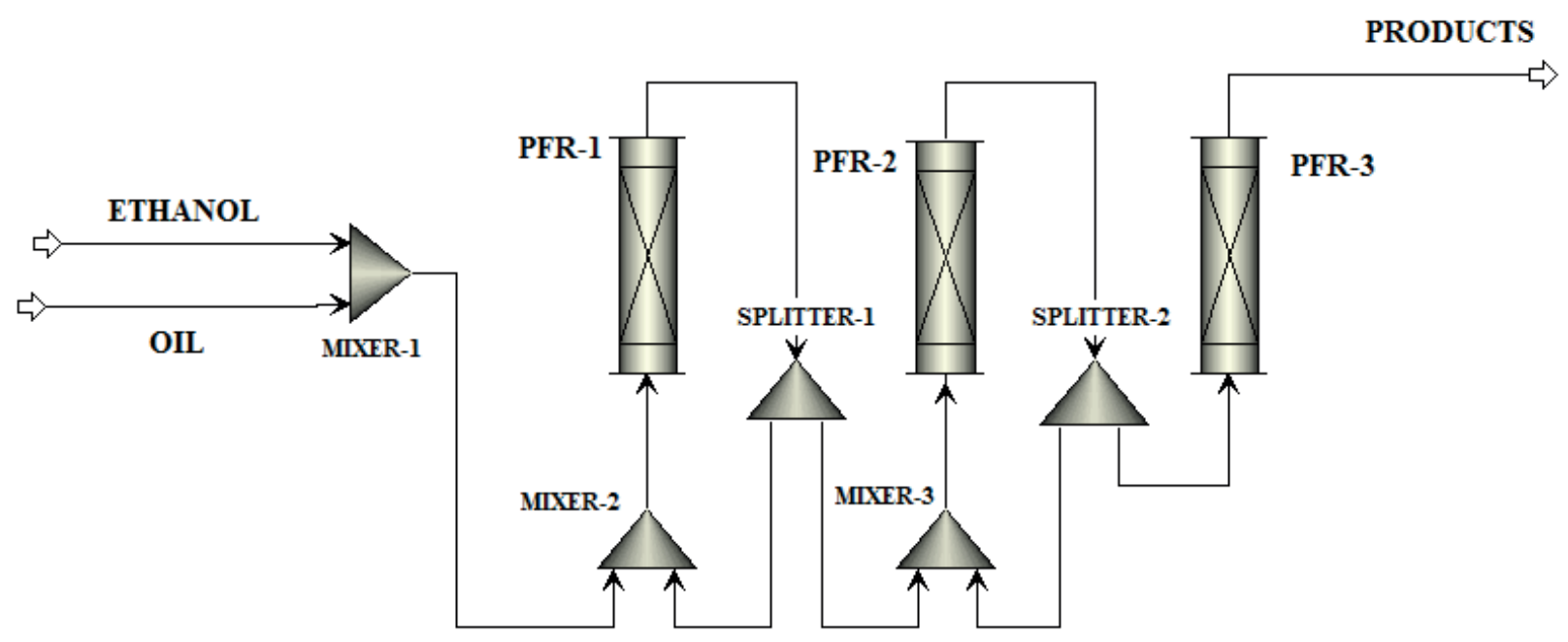

Figure 1. Flowsheet of mini pilot plant for biodiesel production via plug flow reactors (PFRs) with recycle streams

Table 1. Experimental and simulated conditions of biodiesel production process via PFR reactors.

\begin{tabular}{lc}
\hline Raw material & Triolein \\
Homogeneous catalyst & $\mathrm{NaOH}$ \\
Ratio ethanol/oil & $6 / 1$ \\
Feed stream flow rate $(\mathrm{kg} / \mathrm{h})$ & 123.1 \\
Reactor subroutine & $\mathrm{R}$ Plug \\
Temperature of reactor & $60^{\circ} \mathrm{C}$ \\
Pressure of reactor & $1 \mathrm{~atm}$ \\
Temperature of ethanol/oil & $60^{\circ} \mathrm{C}$ \\
Density of oil/ethanol mixture $(\mathrm{kg} / \mathrm{m} 3)$ & 878 \\
Diameter of reactor x length $(\mathrm{m})$ & $0.05 \times 0.7$ \\
\hline
\end{tabular}

the volumetric flow rate meter regulator and the reflux valve of condensed liquid at the top of column. The dosage level of the catalyst in the process and the temperature at the top and base of the column could also be specified via hardware. The pilot plant for biodiesel production that uses reactive distillation with recycle streams is shown in Figure 2.

Based on simulated results the initial experimental tests in the reactive distillation column were performed according to the operating parameters established in Aspen Plus. Oil was initially heated up to $55^{\circ} \mathrm{C}$ before being pumped to the top column stage. Volumetric flow rates of feeding oil and ethyl alcohol were $43.2 \mathrm{~L} / \mathrm{h}$ and $31.1 \mathrm{~L} / \mathrm{h}$, respectively, which provided a molar ratio of 12/1 (alcohol/oil). Before being injected at the bottom of the column the alcohol stream had been totally vaporized after passing through the reboiler. The average temperature of the column was $75^{\circ} \mathrm{C}$ and the final product was obtained at the bottom. Ester and glycerol were generated by a transesterification reaction due to a counter current flow between the ascending vapor of the alcohol and the descending flow of oil and condensed ethyl alcohol. The catalyst was added into the recycle stream, which continuously returned condensed alcohol at the top of column. This catalyst flowed downward in order to promote an efficient operation and its mass fraction ratio relating to the feeding oil was $0.01 \%$. All experiments carried out in the reactive distillation were performed with total reflux. The mini pilot plant of the reactive distillation process is shown in Figure 2 with the oil entering the top and the vaporized alcohol entering at the bottom of the column. Alcohol vapor provides the energy necessary to heat the process, required by a transesterification reaction.

The excess alcohol used in the process was condensed, and returned to the top via reflux stream, which received the catalyst. The reactive distillation column had collecting sections spaced at $0.25 \mathrm{~m}$ intervals, making a total of six sampling points. The thermodynamic models UNIFACDMD and UNIFAC-LLE were used to represent the liquidvapor and the liquid-liquid equilibria in the biodiesel process (Souza et al., 2014). The operating conditions of the pilot plant for biodiesel productions via reactive distillation column are shown in Table 2. 
Factorial Design for Biodiesel Production via Reactive Distillation

The factorial design for obtaining experimental data in the mini pilot plant of reactive distillation is shown in
Table 3. The variables examined were molar ratio between alcohol and cottonseed oil, reflux ratio (yes or no), and sampling points. The results from both the experimental and the simulated tests were compared.

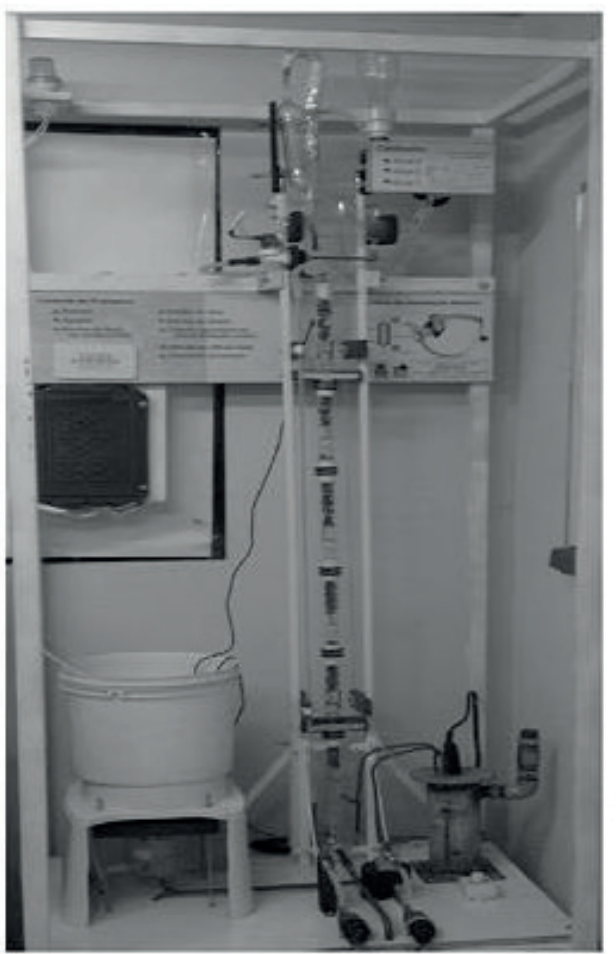

Figure 2. Reactive Distillation Column for biodiesel production process.

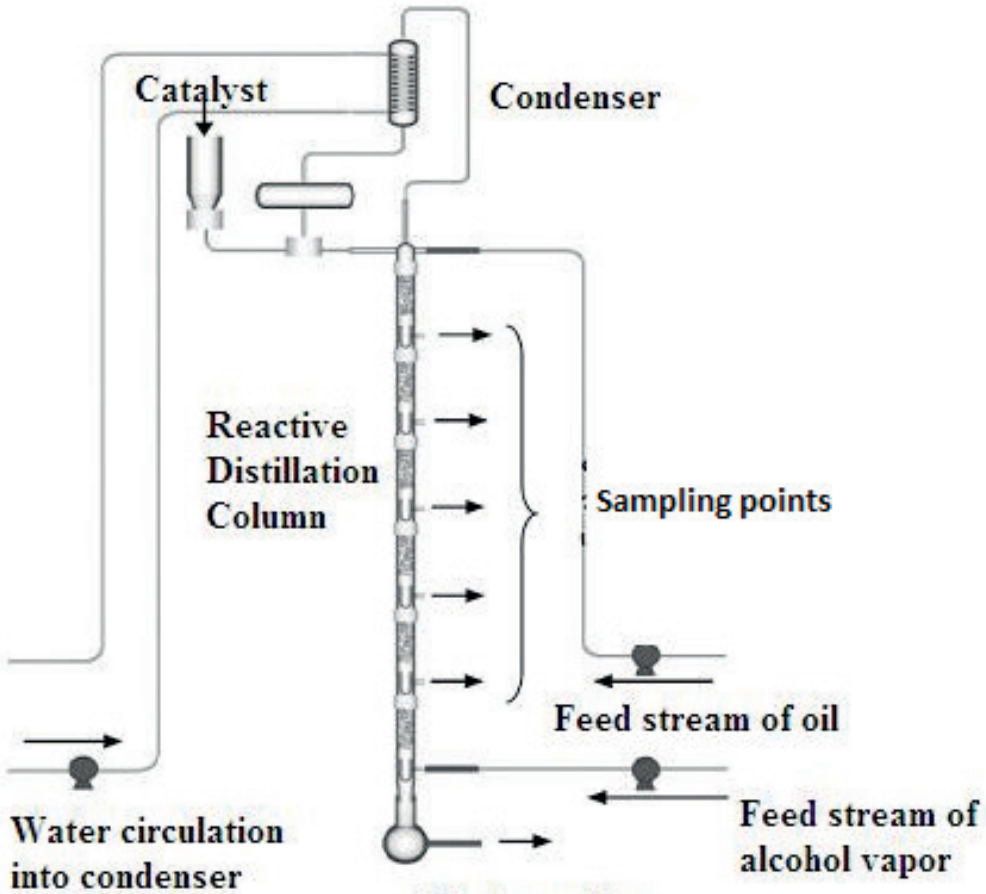

Final sampling point

Table 2. Experimental and simulated conditions of biodiesel production process via reactive distillation.

Raw material
Homogeneous catalyst
Molar Ratio ethanol/oil
Flow of oil stream $(\mathrm{L} / \mathrm{h})$
Flow of alcohol stream $(\mathrm{L} / \mathrm{h})$
Subroutine of distillation column
Temperature of alcohol stream $\left({ }^{\circ} \mathrm{C}\right)$
Temperature of oil stream $\left({ }^{\circ} \mathrm{C}\right)$
Pressure of reactor $($ atm $)$
Thermodynamic model
Height x Internal diameter $(\mathrm{m})$
Reflux Ratio
Flooding fraction of column

Triolein
$\mathrm{NaOH}$
$12 / 1$ or $17 / 1$
43.2
31.1
RadFrac
85
60
1
UNIFAC-DMD
$1.5 \times 0.03$
Total
0.6

Table 3. Factorial design for experiments in the reactive distillation column.

\begin{tabular}{|c|c|c|}
\hline Experiment & Ethanol/Oil MolarRatio & $\begin{array}{c}\text { Ethanol } \\
\text { Reflux } \\
\text { Ratio }\end{array}$ \\
\hline 1 & $12 / 1$ & No \\
\hline 2 & $12 / 1$ & Yes \\
\hline 3 & $17 / 1$ & No \\
\hline 4 & $17 / 1$ & Yes \\
\hline
\end{tabular}




\section{Characterization of Components}

The ester conversion was determined according to the European Standard Method EN 14103 (2011) by using a GC-Master gas chromatography with flame ionization detector and a capillary carbowax column. In order to stop the transesterification reaction an adequate amount of sulfuric acid was added to the samples. The resulting salts were removed by acid and neutral washing followed by centrifugation at $8000 \mathrm{rpm}$ to separate the washing water from the biodiesel. After this, all samples were centrifuged and dried at $120^{\circ} \mathrm{C}$ for four hours.

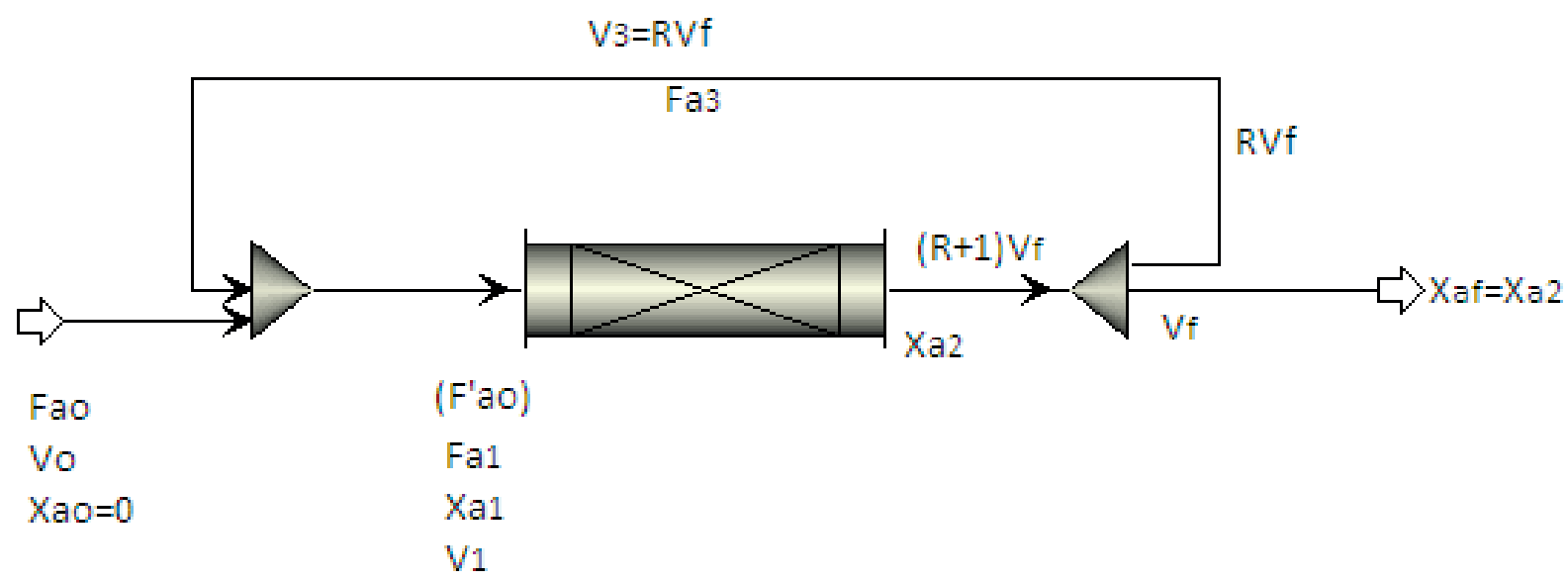

\section{Study of Performance Equation for Plug Flow Reactor with Recycle Stream.}

In order to permit the final product to meet expected conversions and to minimize the cost of an industrial project, performance equations must be used to estimate the correct size for the chemical reactors. Figure 3 shows a PFR with a recycle stream.

Here is a description by Levenspiel (1999) of the performance equation, Eq. (1), for a PFR with recycle stream.

Figure 3. Diagram of a PFR with recycle stream

$$
V=F_{A O}(1+R) \int_{R X f /(1+R)}^{X f} d X A /\left(-r_{A}\right)
$$

where $\mathrm{V}$ is the volume of the reactor (m3), FAO is the mass flow rate of the feeding stream $(\mathrm{kg} / \mathrm{h}), \mathrm{R}$ is the recycle ratio, $\mathrm{Xf}$ is the conversion of products, and (-rA) is the kinetic expression of the chemical reaction.

Souza (2015) described the kinetics of the transesterification reaction of cotton seed oil assuming the following reaction, as shown in Eq. (2).

$$
\text { Oil }+3 \text { Alcohol } \rightarrow 3 \text { Ester }+ \text { Glycerol }
$$

is expressed by Eq.(3):

$$
\frac{-d C_{T G}}{d t}=k C_{T G} C_{A}
$$

where $\mathrm{k}, \mathrm{CTG}$ and $\mathrm{CA}$ are the kinetic constant, the concentration of triglycerides and alcohol, respectively. From Eq. (4)

$$
C_{A}=C_{A O}-3\left(C_{T G O}-C_{T G}\right)
$$

where $\mathrm{CAO}$ and $\mathrm{CTGO}$ represent the initial concentrations of alcohol and triglycerides, respectively.

Substituting the kinetic expression (-rA) in Eq. (5), the resulting expression, after a number of algebraic manipulations, is:

$$
T=\frac{(1+R)}{\left(3 C_{T G O} k\right)} \ln \left[\frac{\left(2-X_{G}\right)\left(1+R\left(1-X_{G}\right)\right.}{\left(1-X_{G}\right)\left(2+R\left(2-X_{G}\right)\right.}\right]
$$

This last expression shows the dependence between the residence time $T$, recycle ratio $R$ and conversion $X G$ inside a plug flow reactor. This expression was used for evaluating the effect of the recycle ratio on ester conversion by Matlab. Souza (2015) carried out a kinetic study of the transesterification reaction using cotton seed oil and determined the kinetic parameters, estimated with experimental data where the activation energy was $27.48 \mathrm{~kJ}$ mol-1, and the frequency factor was $\mathrm{ko}=8173 \mathrm{dm} 3 /(\mathrm{mol}$ $\min )$ at $60^{\circ} \mathrm{C}$. Under the operating conditions of the mini pilot plant, the concentration CTGO was $0.5 \mathrm{~mol} / \mathrm{L}$. The residence time required for a desired conversion of $98 \%$, varying the recycle ratio from 0 to 100 was also studied. 
The relationship between the volume of a chemical reactor (V) in $\mathrm{m} 3$ and its residence time (T) is shown in Eq. (6).

$$
V=T^{*} Q
$$

where $\mathrm{Q}$ is the volumetric feed flow of reactants ( $3 / \mathrm{min})$. By evaluating the residence time required to convert $98 \%$ of triglycerides into esters, we could then predict the required number of PFRs. Ester conversion was also evaluated in the product stream at the bottom of the column and the performance of both processes compared.

\section{RESULTS AND DISCUSSION}

\section{Biodiesel Production Process via Plug Flow Reactors (PFRs)}

The mini pilot plant for biodiesel production that uses PFRs with recycle streams reached an average conversion of $10.3 \%$, with 0 recycle. Considering the operating conditions of the process and based on Equation 5, this was the highest conversion that could be achieved, with an optimal recycle rate. Furthermore, further experiments were avoided to save material. Results of simulations in ASPEN PLUS ${ }^{\circledR}$ obtained after increasing the recycle ratio in the PFRs are shown in Table 4.

Table 4. Simulated results in ASPEN Plus between the increase in recycle ratio and ester conversion for the plug flow reactors

\begin{tabular}{lcccccc}
\hline Recycle ratio (\%) & 0 & 10 & 20 & 30 & 40 & 50 \\
Simulated Conversion (\%) & 16.5 & 14.7 & 13.2 & 10.0 & 8.1 & 2.1 \\
\hline
\end{tabular}

The simulated results indicated that the effect of increasing the recycle ratio was to decrease chemical conversion. Moreover, the highest ester conversion of 16.5 does not meet the requirements of standard specifications such as EN14142 and RE ANP n ${ }^{\circ} 14$ (EN14142, 2010 and ANP, 2012), which establish $96.5 \%$ as the minimal mass fraction for commercial use of biodiesel. Figure 4 shows the relation between the recycle ratio and the residence time for an estimated conversion in esters of $98 \%$.

Figure 4 shows the increase in residence time associated with a recycle ratio variation from 0 to 100.The minimal residence time occurs when the recycle ratio is 0 . Even though high conversions in PFRs are possible, when the recycle ratio is increased, their performance become similar to that in a CSTR reactor and the global efficiency of the process is reduced. Consequently, in order to obtain $98 \%$ conversion into esters, the best condition is the one with 0 recycle ratio. The use of baffles is also recommended to provide an efficient agitation inside a PFR.

The expression obtained in Eq. (4) was used to create a 3D map in MATLAB, showing the profile between the recycle ratio, conversion and residence time (Figure 5).

In Figure 5, the light area up on the left side shows an undesirable condition for the biodiesel production process in a PFR. This is due to an extended residence time required for high ester conversion. In contrast, low conversions associated with low residence times and recycle rates are situated in the dark area at the bottom left, illustrating inadequate working conditions. According to the 3D map, the ideal region for operating PFRs is situated in the dark region at the bottom right with low recycle ratios and high conversions. Despite the initial purpose of constructing a system with recycling to obtain high conversion rates, the simulated data showed a negative effect on overall efficiency. These results show that further studies of the biodiesel production process via PFRs are also required.

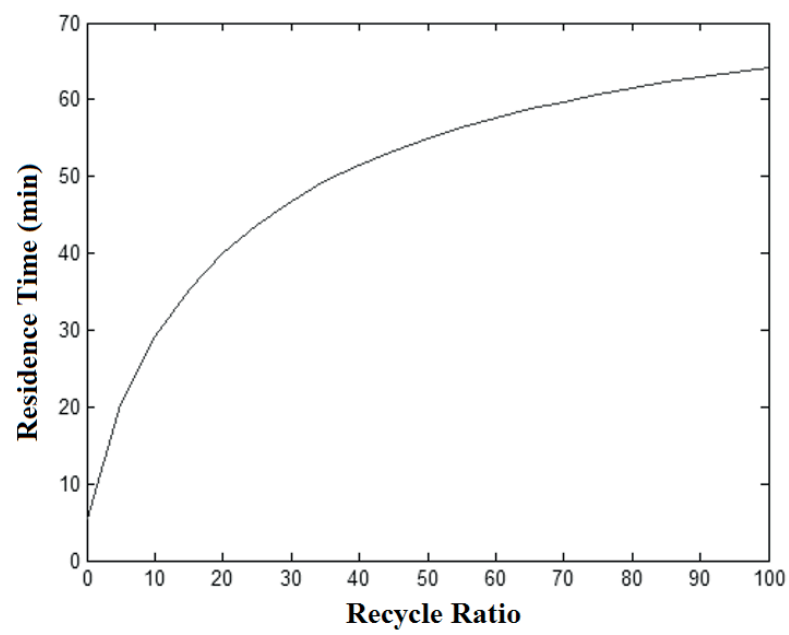

Figure 4. Progress of residence time according to the recycle ratio for a defined conversion of $98 \%$

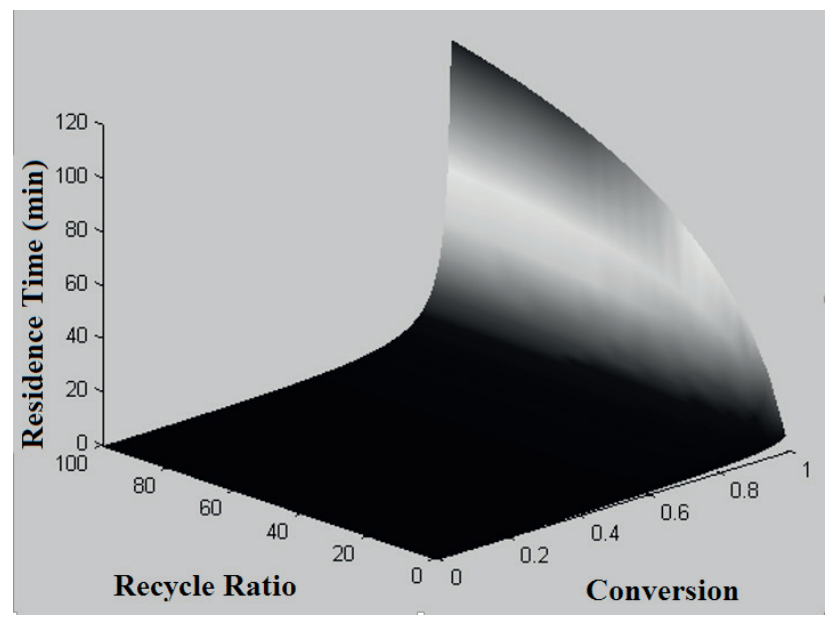

Figure 5. 3D map created in Matlab ${ }^{\circledR}$ for PFRs with recycle streams. 


\section{Biodiesel Production Process via Reactive Distillation}

The total time of $20 \mathrm{~min}$ for operating the reactive distillation process was three times faster than the conventional batch process. Figure 6 shows a comparison between experimental and simulated results obtained via reactive distillation.

The trend line equation shown in Figure 6, for the experimental points is given by Eq. 7

$$
y(x)=-0.587 x^{2}+15.238 x-8.99 ; r^{2}=0.9874
$$

The increasing conversions throughout the column reached a maximum of approximately $60 \%$ at the bottom (sampling point 6). All experimental results agreed with those previously simulated. The simulated results for 6 theoretical stages are similar to the experimental data for a packing height of $1.5 \mathrm{~m}$ of the column, indicating a theoretical stage equivalent height (HETP) of $0.25 \mathrm{~m}$. Figure 7 shows the composition profiles inside the reactive distillation column.

Figure 7 illustrates that in the first two stages ethanol and oil are the major components. This is mainly due to the fact that alcohol is continuously recycled at the top of the column and the oil stream is situated in the second stage. Differently, glycerin and biodiesel are gradually produced in a top down direction and they reach a maximum of production at the bottom of the column. The energy required by the distillation column was $5.8 \mathrm{~kW}$ in the simulation study and it was $6.4 \mathrm{~kW}$ in the experimental run, since there was heat loss throughout the column.

This similarity between experimental and simulated results constituted a basis for continuing the factorial design. Figure 8 shows the results obtained after performing the experimental analysis in the reactive distillation column based on previous factorial design.

Figure 8a shows an increase of ester conversion from top to the bottom of the reactive distillation column. This is because a higher reaction time is verified for the final sampling points. Figure $8 \mathrm{~b}$ shows that the presence of full recycle at the top of the column contributes to an increase in ester conversion, mainly in the first sections of the column. This is due to the excess of alcohol inside the column, which stimulates the trasensterification reaction.

Similarly to the first condition in Figure.8a, Figure $8 \mathrm{c}$ illustrated an accentuated ester conversion at the final sampling points. However, the ester formation rate at the top is analogous to the second condition, shown in Figure 8b. Although Figure 8d also presents an increase in ester conversion moving down the column, the recycle rate at the top did not affect the conversion significantly. Due to this fact we concluded that, for this experiment, the maximum molar ratio of alcohol/oil was approximately 17/1.

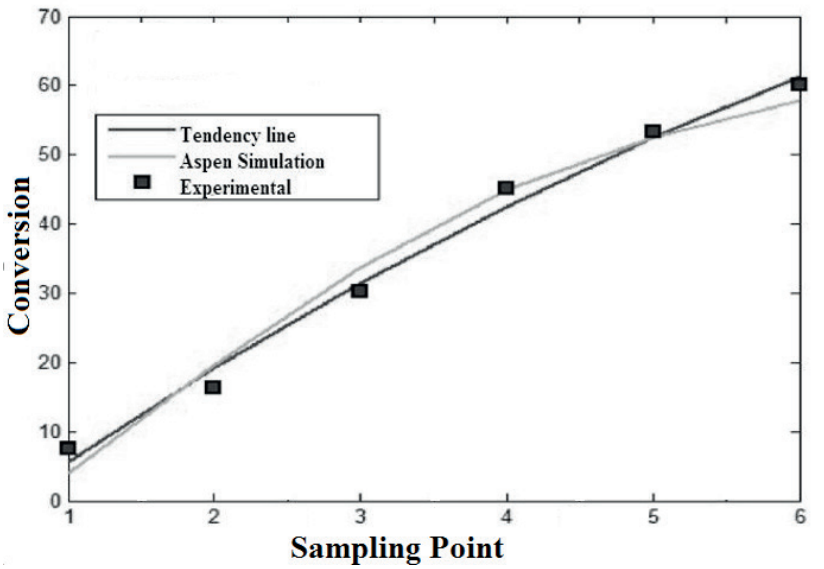

Figure 6. Comparison between experimental and simulated conversion obtained by reactive distillation.

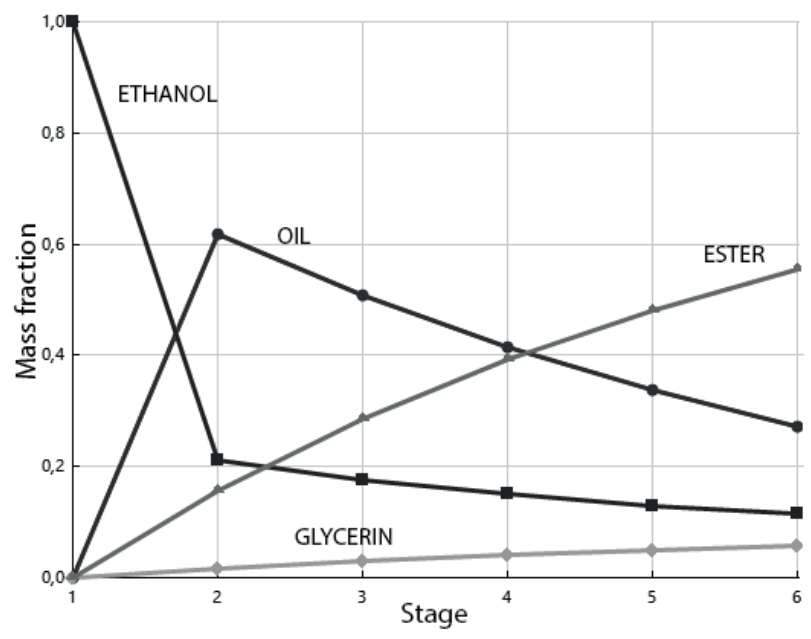

Figure 7. Composition profiles of reactants and products in the reactive distillation obtained in the simulation study (mass fraction).

\section{Comparison between PFRs and Reactive Distillation}

Figure 4 shows that, for a condition of 0 recycle, a residence time of 5.3 minutes $(0.09 \mathrm{~h})$ was required to perform the transesterification reaction. Adopting a feed flow into the first reactor, as shown in Figure 1, of 123.1 $\mathrm{kg} / \mathrm{h}$ and considering the density of $878 \mathrm{~kg} / \mathrm{m} 3$, provided by ASPEN PLUS, the volumetric flowrate $\mathrm{Q}$ becomes 0.14 $\mathrm{m} 3 / \mathrm{h}$.

Consequently, the optimum volume of the required reactor was $0.0126 \mathrm{~m} 3$. The PFRs in the mini pilot plant at the laboratory have an individual volume of $0.0014 \mathrm{~m} 3$. In this situation, the possibility of achieving conversions near to $98 \%$ via PFRs with recycling can only happen by a drastic reduction of the volumetric flow rate. This, however, does not fit with the purpose of producing biodiesel on a massive scale. 


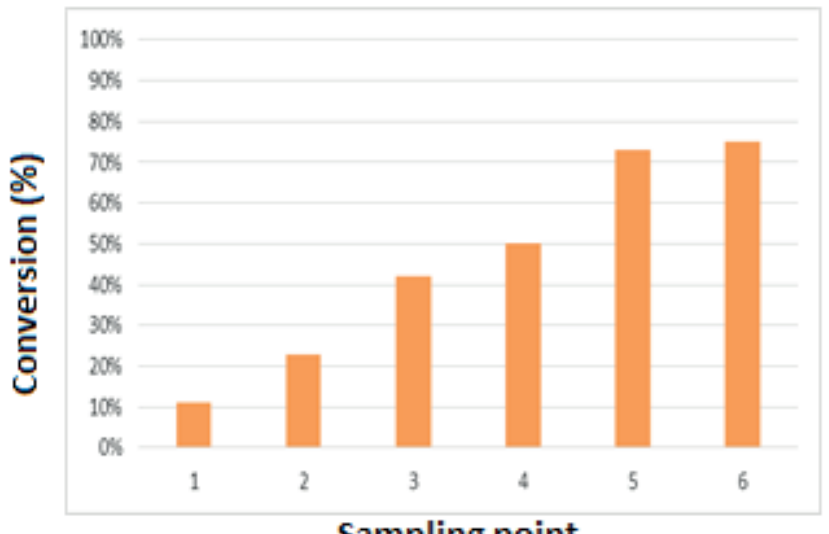

Sampling point

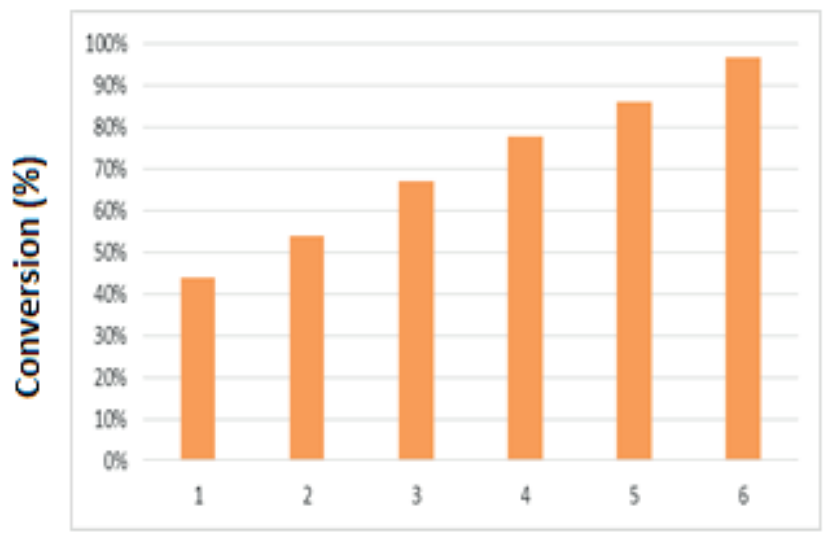

Sampling point b
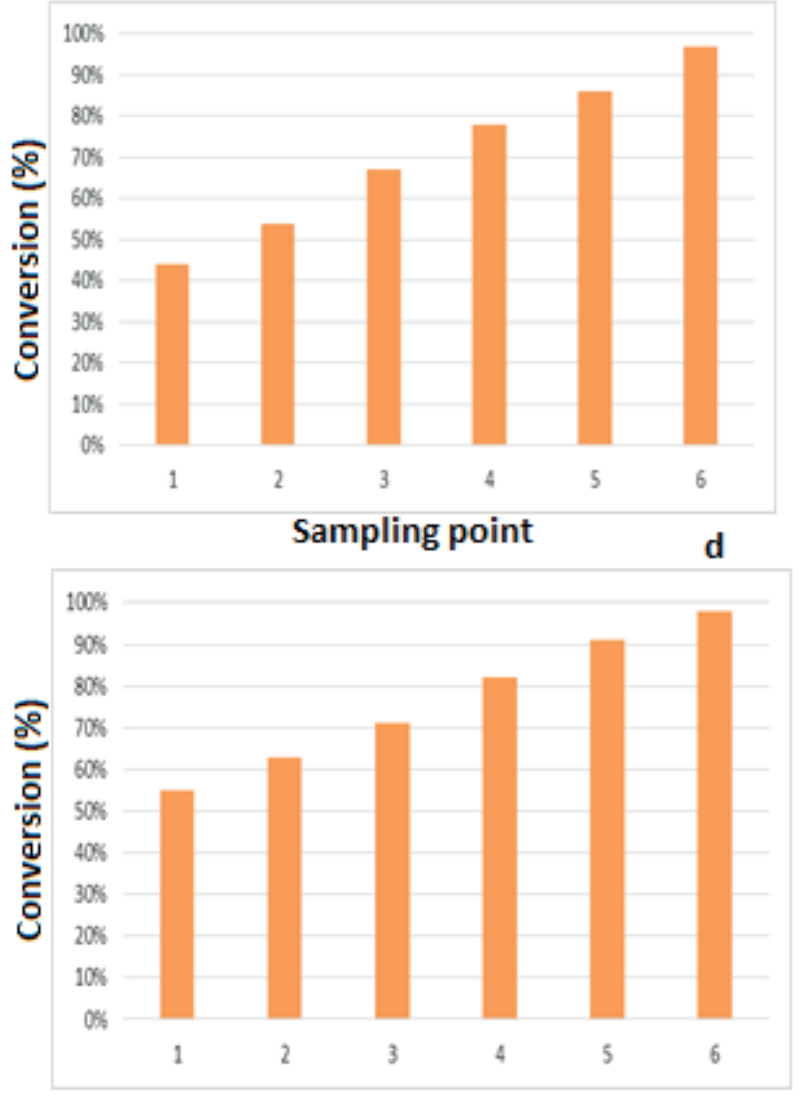

Sampling point

Figure 8. Variation of ester conversion according to sampling point throughout the column under different operating conditions: a) alcohol/oil molar ratio of 12/1 and without recycle ratio; b) alcohol/oil molar ratio of 12/1 and full recycle; c) alcohol/oil molar ratio of 17/1 and without recycle ratio; d) alcohol/oil molar ratio of 17/1 and full recycle.

Considering the operating condition of the pilot plant, 9 PFRs with the same diameter would be required for an ester conversion of $98 \%$. By contrast, conversions near to $98 \%$ were possible by a single reactive distillation column operating at an alcohol/oil molar ratio of $12 / 1$, as shown in Figure $8 \mathrm{~b}$. Thus, the reactive distillation technique is the most adequate and promising continuous process to meet future demands for biodiesel.

\section{CONCLUSION}

After reproducing the initial conditions of a biodiesel mini pilot plant via PFR in ASPEN PLUS, we verified that low conversions of esters were obtained. These conversions decreased with the increase of the recycle ratio. A 3D map, based on a PFR performance equation, showed that high recycle ratios and conversions are also associated with longer residence times, leading to the construction of larger units and an increase in the cost of the process. We found that, for a conversion of $98 \%(\mathrm{~m} / \mathrm{m})$ into esters, 9 PFRs of the same volume are required.

In contrast, a single reactive distillation column was able to convert $98 \%$ of oil into ester, as shown in Figure $7 \mathrm{~b}$. Indeed, the recycle ratio of alcohol at the top of the column positively affected the purity of ester along the column and the optimized condition was found at an alcohol/oil molar ratio of 12/1. Furthermore, the innovative reactive distillation technique shows an excellent potential for meeting the global demand for biodiesel via a continuous process.

\section{NOMENCLATURES}

ANP - National Agency of petroleum, natural gas and biofuels

ASTM - American Society for Testing and Materials

PFR - Plug Flow Reactor

EN14214 - European Specifications for Biodiesel Fuels

UNIFAC - Universal Functional Activity Coefficient 


\section{ACKNOWLEDGEMENTS}

We thank PRH-28/ANP/PETROBRAS, FINEP, RECAT, CAPES/PROCAD, CETENE, National Council for Scientific and Technological Development (CNPq) and INCT-EMA for the financial support required to develop this research. English revision by Sidney Pratt.

\section{REFERENCES}

Alves, M. J. S., Nascimento, M., Pereira, I.G., Maria, I. M., Cardoso, V. L and Reis, M. Biodiesel purification using micro and ultrafiltration membranes, Renew. Energy, 58 (1), 15-20 (2013).

ASTM Method D6751-12, Standard specification for biodiesel fuel (B100) blend stock for distillate fuels. In: Annual Book of ASTM Standards, ASTM International, West Conshohocken. (2012).

Beckmann, A. F. Nierlich., Popken, T., Reusch, D and Tuchlenski, V. S. C. A., Industrial experience in the scale-up of reactive distillation with examples from C4-chemistry.Chem. Eng. Sci., 57 (9), 1525-1530 (2002).

Boon-anuwat, N., Kiatkittipong,W., Aiouache, F and Assabumrungrat, S. Process design of continuous biodiesel production by reactive distillation: Comparison between homogeneous and heterogeneous catalysts. Chem. Eng. Process: Process Intensif., 92(1),33-44 (2015).

Choedkiatsakul I., Ngaosuwanb K., Cravottoc, G and Assabumrungrat, S. Biodiesel production from palm oil using combined mechanical stirred and ultrasonic reactor, Ultrason. Sonochem. 21 (4), 1585-1591 (2014).

Dhar, B. R and Kirtanai, K., Excess methanol recovery in biodiesel production process using a distillation column: a simulation study. Chem. Eng. Res. Bull., 13 (2), 55-60 (2009).

EIA - U.S. Energy Information Administration. Annual Energy Outlook 2012 with Projections to 2035. Washington, DC. http://www.eia.gov/forecasts/aeo/pdf/0383(2012).pdf. accessed on 21.08.2015.

EN 14103: Fat and oil derivatives - Fatty Acid Methyl Esters (FAME) -Determination of ester and linolenic acid methyl esters content, 2011.

EN 14214: AutomotiveFuels- Fatty Acid Methyl Esters (FAME), Requirements and Test Methods, European standard for biodiesel, 2010.

Festel, G. W., Biofuels-economic aspects. Chem. Eng. Technol. 31(5), 715-720 (2008).

Fogler, H. S., Elements of Chemical Reaction Engineering. Prentice Hall Press, New Jersey (1999).

Gomez-Castroa, F. I., Rico-Ramireza, V., Segovia-Hernandez, J. G. and Hernandez, S., Feasibility study of a thermally coupled reactive distillation processfor biodiesel production, Chem. Eng. Process., 49 (3), 262-269(2010).

He, B. B., Singh, A. P and Thompson, J. C., A novel continuousflow reactor using reactive distillation for biodiesel production, Am. Soc. Agric. Biol. Eng., 49 (1), 107-112 (2006).

Henley, E. J. and Seader, J. D., Separation Process Principles. Wiley, New York (1998).

Holtbruegge, J., Wierschem, $\mathrm{M}$ and Lutze, P., Synthesis of dimethyl carbonate and propylene glycol in a membraneassisted reactive distillation process: Pilot-scale experiments, modeling and process analysis, Chem. Eng. Process. 84 (1), 54-70 (2014).

Ignata, R. M and Kiss, A. A.,Optimal design, dynamics and control of a reactive DWC forbiodiesel production, Chem. Eng. Res. Des. 91(9), 1760-1767(2013)

Jain, S. K., Kumar, S and Chaube, A., Technical sustainability of biodiesel and its blends with diesel in c.i. engines: a review. Intern.J. Chem. Eng. Applic. 2 (2), 101-109 (2012).

Joseph, P., Soy in the amazon. The Virginia Quarterly Review, 83(4), 107-121 (2007). Kiss, A. A., Heat-integrated reactive distillation process for synthesis of fatty esters, Fuel Process. Technol., 92(7), 1288-1296 (2011).

Levenspiel, Octave. Chemical Reaction Engineering. 3rd Edition. New York: John Wiley \& Sons (1999).

Machado, G. D., Pessoa., F. L. P., Castier, M., Aranda, D. A. G., Cabral, F.V., and Cardozo-Filho, L., Biodiesel Production by Esterification of Hydrolyzed Soybean Oil with Ethanol in Reactive Distillation Columns: Simulation Studies, Ind. Eng. Chem. Res., 52(27), 9461-9469 (2013)

National Agengy of Petroleum, Natural Gas and Biofuel, ANP. Resolution $N^{\circ} 14$ of 11.5.2012 - DOU 18.5.2012.Biodiesel Especification of Technical Note ANP n ${ }^{\circ} 4$ (2012).

Pinto, A. C., Guarieiro, L. L. N., Rezende, M. J. C., Ribeiro, N.M., Torres, E.A., Lopes, W.A., Pereira, A.P and Andrade, J. B. Biodiesel: an overview. J. Braz. Chem. Soc., 16 (6), 13131330 (2005).

Qian, J., Wang, F., Liu, S and Yun, Z., In situ alkaline transesterification of cottonseed oil for production of biodiesel and nontoxic cottonseed meal. Bioresour.Technol. 99 (18), 9009-9012 (2008).

Simasatitkul, L., Siricharnsakunchai, P.,Patcharavorachot, Y., Assabumrungrat, Sand Arpornwichanop, A., Reactive distillation for biodiesel production from soybean oil, Korean J. Chem. Eng., 28(3), 649-655 (2011).

Souza, T. P. C., Produção de biodiesel via rota Etílica por destilação reativa, extrativa e absortiva: uma Comparação experimental e computacional. Ph.D. Thesis, Federal University of Pernambuco, Brazil (2015).

Souza, T. P.C., Stragevitch, L., Knoechelmann, A., Pacheco, J. G. A. and Silva, J.M.F., Simulation and preliminary economic assessment of a biodiesel plant and comparison with reactive distillation, Fuel Process Technol., 123 (1), 75-81 (2014).

Teo, C. L., Jamaluddin, H., Zain, N. A. M and Idris A., Biodiesel production via lipase catalysed transesterification of microalgae lipids from Tetraselmis sp., Renew. Energy. 68 (1), 1-5 (2014).

Yang, F., Hanna, M.A and Sun, R., Value-added uses for crude glycerol-a byproduct of biodiesel production, Biotech. Biofuels, 5 (1), 1-10 (2012). 